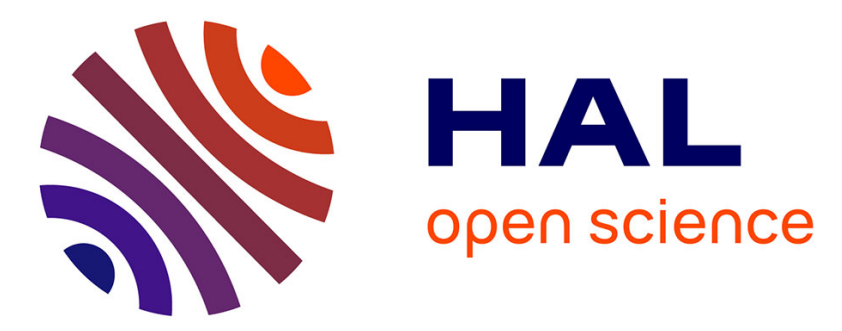

\title{
L-band compact printed quadrifilar helix antenna with 'Iso-Flux' radiating pattern for stratospheric balloons telemetry
}

Nelson Fonseca, Sami Hebib, Hervé Aubert

\section{To cite this version:}

Nelson Fonseca, Sami Hebib, Hervé Aubert. L-band compact printed quadrifilar helix antenna with 'Iso-Flux' radiating pattern for stratospheric balloons telemetry. Antennas and Propagation Society International Symposium, 2008, IEEE, Jul 2008, San Diego, United States. pp. 1-4, 10.1109/APS.2008.4619229 . hal-00432239

\section{HAL Id: hal-00432239 \\ https://hal.science/hal-00432239}

Submitted on 15 Nov 2009

HAL is a multi-disciplinary open access archive for the deposit and dissemination of scientific research documents, whether they are published or not. The documents may come from teaching and research institutions in France or abroad, or from public or private research centers.
L'archive ouverte pluridisciplinaire HAL, est destinée au dépôt et à la diffusion de documents scientifiques de niveau recherche, publiés ou non, émanant des établissements d'enseignement et de recherche français ou étrangers, des laboratoires publics ou privés. 


\title{
L-Band Compact Printed Quadrifilar Helix Antenna with 'Iso-Flux' Radiating Pattern for Stratospheric Balloons Telemetry
}

\author{
Nelson J.G. Fonseca* ${ }^{(1)}$, Sami Hebib ${ }^{(2,3)}$, and Hervé Aubert ${ }^{(2,4)}$ \\ (1) CNES, 18 av. Edouard Belin, 31401 Toulouse, France \\ (2) LAAS - CNRS, University of Toulouse, \\ 7 av. Du Colonel Roche, 31077 Toulouse, France \\ (3) LAME - UPS, 118 Route de Narbonne, 31062 Toulouse, France \\ (4) INPT - ENSEEIHT, 2 rue Charles Camichel, 31071 Toulouse, France \\ E-mail: nelson.fonseca@cnes.fr
}

\section{Introduction}

Quadrifilar helix antennas have very interesting characteristics. For instance, by selecting properly the height and number of turns of the helix, one can achieve a radiation pattern of so-called 'iso-flux' shape with high gain at low elevation. Such a pattern enables to improve the link budget for stratospheric balloons telemetry as the gain of the antenna compensate for the free space propagation losses. The French Space Agency (CNES) has been working on the topic for years and has patented a simple to manufacture and low-cost Printed Quadrifilar Helix $(\mathrm{PQH})$ antenna with integrated feeding network [1], particularly adapted to short missions with no material reuse.

More recently, CNES has worked with Systems Analysis and Architecture Laboratory of the French Research Agency (LAAS-CNRS) on the axial length reduction of the $\mathrm{PQH}$ antenna with 'iso-flux' pattern since balloons payload improvements were asking for antenna improvements too. Various size-reduced helix antennas are presented in the literature, but they present mainly hemispherical patterns and the cross-polarization degradation induced by the sizereduction technique is usually not addressed $[2,3]$. The authors previously proposed to use pre-fractal and quasi-sinusoidal curves which led to sizereductions between $33 \%$ and $38 \%$ [4, 5], but the achieved co-polarization patterns have some non-conformities that needed to be improved.

In this communication, we propose two new designs based on sinusoidal profiles. Antenna height reduction ranges from 33 to $39 \%$ with no significant degradation of the main performances. Cross-polarization level remains similar to the reference antenna performances and co-polarization pattern is now fully compatible with stratospheric balloons telemetry 'iso-flux' specifications.

\section{Antennas design description}

The PQH antenna is composed of 4 straight wires printed on a thin substrate that is then rolled to form the helix. The feeding network produces the same amplitude 
at each wire input and a phase progression of $90^{\circ}$. Such a configuration results in good circular polarization. The previously developed software [4, 5] has been adapted to include basic curves defined by the superposition of $N$ sinusoidal functions according to the following formula:

$$
y=A_{0} \sin \left(2 \pi \frac{x}{T}\right)+\sum_{k=1}^{N-1} A_{k} \sin \left(2 \pi \sigma_{k} \frac{x}{T}\right), \quad 0 \leq x \leq T
$$

where $A_{k} / A_{0}$ is the amplitude ratio for the $\mathrm{k}^{\text {th }}$ sinusoidal function $1 / \sigma_{k}$ is the period ratio for the $\mathrm{k}^{\text {th }}$ sinusoidal function

A basic curve is defined over one period of the so-called 'fundamental' sinusoidal function, characterized by the longer period. Depending on the period and amplitude ratios, various basic curves can be analyzed as illustrated in fig. 1. A radiating wire of the $\mathrm{PQH}$ antenna is then composed of the repetition of basic curves, the period being scaled so that the total length of the 'unfolded' wire is somewhat similar to the reference one. Mathematical transformations are then applied to the points defining the wires to incline them and produce the cylindrical shape. Basic curve repetition ranges typically from 1 to 20 and the number of combined sinusoidal functions remains lower than 2 or 3 to keep the number of points defining the radiating wires compatible with a parametric analysis process in terms of computation time.

Two profiles were finally selected for their interesting radiating patterns. They are referred to as SP-PQH 1 and 2 (Sinusoidal Profile PQH antenna). The planar layouts of the proposed SP-PQH antennas are compared to the reference one in fig. 2. SP-PQH1 is characterized by a single sinusoidal basic curve whereas SP$\mathrm{PQH} 2$ is the combination of two sinusoidal functions with a period ratio of 2 . The basic curve of each antenna is repeated 10 times. Further geometrical characteristics are given in table 1.

\begin{tabular}{c|c|c|c}
\hline \hline & Reference PQH & SP-PQH1 & SP-PQH2 \\
\hline Axial length & $293 \mathrm{~mm}$ & $196 \mathrm{~mm}$ & $178 \mathrm{~mm}$ \\
Wire length & $329 \mathrm{~mm}$ & $351 \mathrm{~mm}$ & $329 \mathrm{~mm}$ \\
Inclination angle & $63^{\circ}$ & $54^{\circ}$ & $61^{\circ}$ \\
Size reduction & - & $33,1 \%$ & $39,3 \%$ \\
\hline \hline
\end{tabular}

Table 1 - Geometrical characteristics of SP-PQH antennas compared to reference antenna

\section{Simulation results and discussion}

The proposed PQH antennas were analyzed using the Method of Moments based commercial tool ASERIS-EMC2000( (EADS CCR). The dielectric substrate supporting the printed wires was not considered since its thickness is small compared to the wavelength. The design frequency is $1775 \mathrm{MHz}$. Simulation results presented in fig. 3 reveal that the proposed SP-PQH antennas have wider bandwidth operation that conventional $\mathrm{PQH}$ antenna. For instance, with a 
specification of $-10 \mathrm{~dB}$, the bandwidth is respectively $2.3,3.2$ and $3.8 \%$ for the reference $\mathrm{PQH}$, the SP-PQH1 and the SP-PQH2 antennas. Simulated radiation patterns of the SP-PQH antennas are compared to the reference one in fig. 4. One can note that the maximum directivity is a bit lower than that of the reference antenna. As we reduce the height of the antenna the maximum directivity at low elevation always decreases and the main beams become wider. This behavior makes it particularly difficult to design compact helix antennas with 'iso-flux'

patterns. Nevertheless, the co-polarization patterns are fully compatible with the 'iso-flux' specification. In the case of SP-PQH1, the cross-polarization level is even improved, as well as the rear radiation.

Manufacturing is now under process for the SP-PQH antennas. Good agreement was found comparing EMC2000 (C) and measurements for the reference antenna. Hence, we can feel confident on the presented results.

\section{Conclusion}

Two sinusoidal profile compact printed Quadrifilar helix antennas have been presented. Particular care has been given to the co and cross-polarization patterns during the parametric design process to produce antennas with performances very similar to the conventional one in those aspects. A size reduction ranging from 30 to $40 \%$ is confirmed. Experimental validation will be presented at the conference.

\section{Acknowledgment}

The authors would like to thank C. Grevet, R. Harbi, B. Monteillet and M. Pascal for the improvements brought to the sinusoidal profile generation software.

\section{References:}

[1] A. Auriol, "Helix-Type Antenna and its Manufacturing Process", European Patent, publication number: 0320404A1, June $14^{\text {th }}, 1989$.

[2] D. K. C. Chew and S. R. Saunders, "Meander Line Technique for Size Reduction of Quadrifilar Helix Antenna", IEEE Antennas and Wireless Propagation Letters, vol. 1, no. 1, pp. 109-111, 2002.

[3] Y. Letestu, A. Sharaiha and P. Besnier, "A Size-Reduced Configuration of Printed Quadrifilar Helix Antenna”, IWAT 2005, March 7-9, 2005, Singapore, pp. 326-328.

[4] Lamyaa Hanane, Sami Hebib, Hervé Aubert and Nelson J.G. Fonseca, "Compact Printed Quadrifilar Helix Antennas for Stratospheric Balloons Telemetry”, IEEE AP-S 2007 Conference Proceedings, June 10-15, 2007, Honolulu, Hawaii, pp. 1525-1528.

[5] Lamyaa Hanane, Sami Hebib, Hervé Aubert and Nelson J. G. Fonseca, "Compact Printed Quadrifilar Helix Antenna with sinusoidal profile for Stratospheric Balloon Telemetry", 4th ESA International Workshop on TT\&C Systems for Space Applications, Sept. 11-14, 2007, Darmstadt, Germany. 


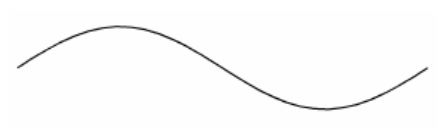

(a)

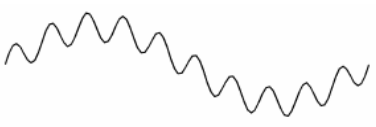

(b)

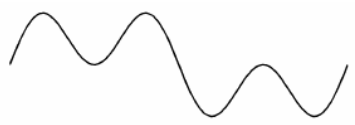

(c)

Fig. 1 - The basic curve can be either (a) a single sinusoidal function or the superposition of two sinusoidal curves with (b) high period ratio or (c) low period ratio

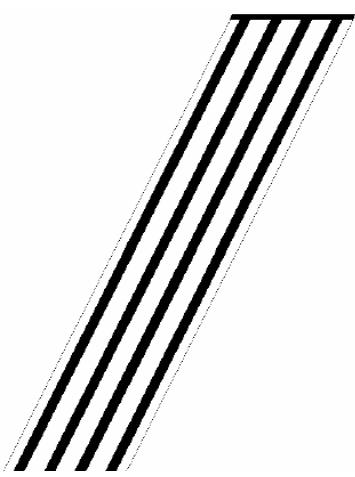

(a)

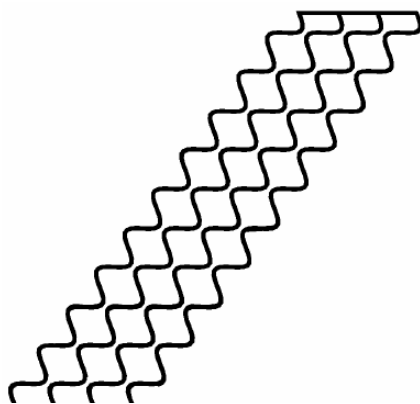

(b)

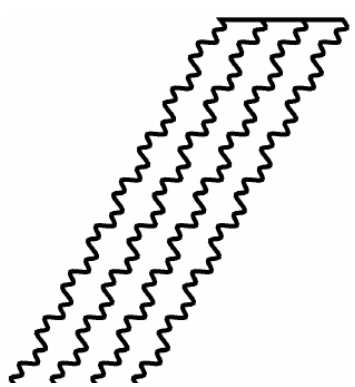

(c)

Fig. 2 - Planar layouts of (a) the reference PQH antenna, (b) SP-PQH1 antenna and (c) SP-PQH2 antenna

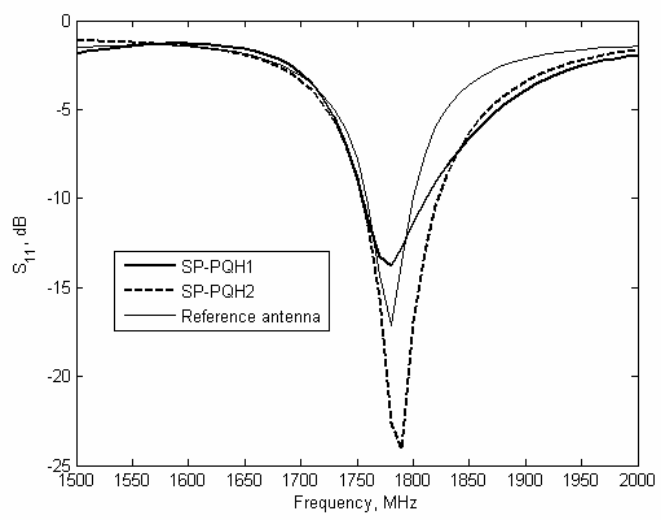

Fig. 3 - Return losses in dB of the SP-PQH antennas designed at $1775 \mathrm{MHz}$

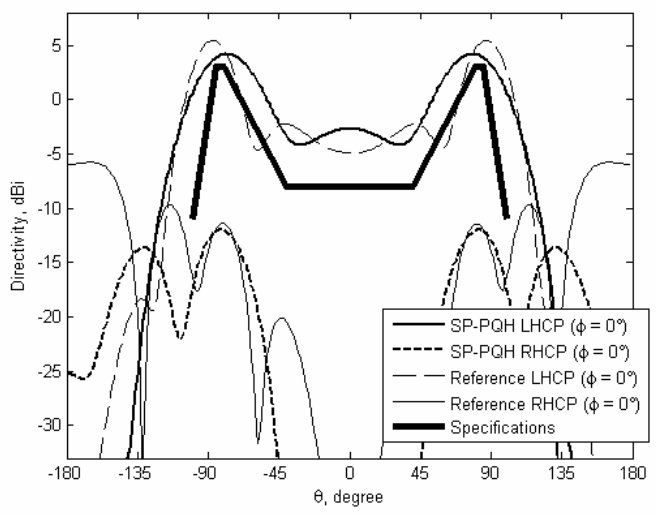

(a)

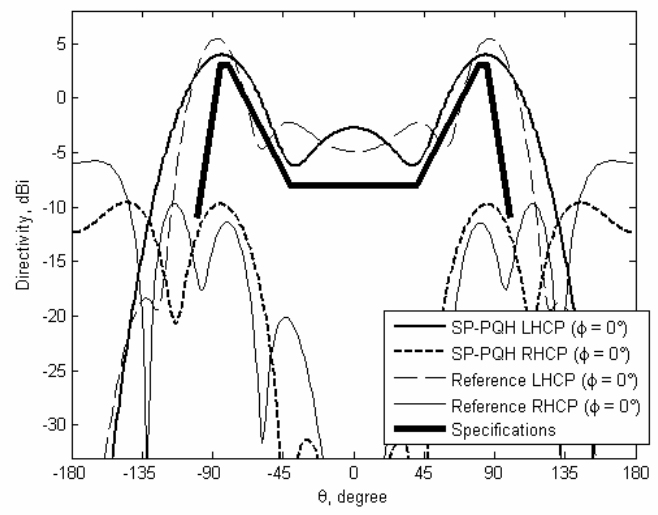

(b)

Fig. 4 - Simulated radiation patterns of (a) SP-PQH1 and (b) SP-PQH2 at $1775 \mathrm{MHz}$ 